\title{
The municipal solid waste and the quality of life of collectors of recyclable materials in Juiz de Fora, Minas Gerais ${ }^{1}$
}

\author{
Aline de Barros Pimenta ${ }^{\mathrm{a},}$, Sueli Maria dos Reis Santos ${ }^{\mathrm{b}}$, Maria Cristina Pinto de Jesus ${ }^{\mathrm{b}}$, Marcos \\ Mantins Borges $^{c}$, Geraldo Luciano de Oliveira Marques ${ }^{\mathrm{d}}$ e José Gustavo Francis Abdalla \\ ${ }^{a}$ An Architect and Urban Planner, Master Student in Built Environment by the Graduate Program in Built \\ Environment (ProAC)of the Federal University of Juiz de Fora, pimenta_aline@yahoo.com.br, Minas Gerais, \\ Brazil \\ ${ }^{\mathrm{b}}$ Nurse, Doctor, Associate Professor at the Faculty of Nursing at the Federal University of Juiz de Fora, \\ sueli.santos@ufjf.edu.br,mcp4@acessa.com, Minas Gerais,Brazil \\ ${ }^{\mathrm{c}}$ An Architect and Urban Planner, Doctor, Associate Professor of the Faculty of Engineering of the Federal \\ University of Juiz de Fora, marcos.borges@engenharia.ufjf.br, Minas Gerais, Brazil \\ ${ }^{\mathrm{d}}$ Civil Engineer, Doctor, Associate Professor of the Faculty of Engineering of the Universidade Federal de Juiz \\ de Fora, geraldo.marques@ufjf.edu.br, Minas Gerais, Brazil \\ ${ }^{\mathrm{e}}$ An Architect and Urban Planner, Doctor, Associate Professor of the Faculty of Engineering of the Federal \\ University of Juiz de Fora, gustavofrancis@ig.com.br, Minas Gerais, Brazil
}

\begin{abstract}
The generation growing and diversified of Municipal Solid Waste is configured as an environmental problem, economic and social deterioration, especially, by application of inappropriate management of them. Faced with this urban context, the research in development presents as specific objective assessment of the quality of life of the gatherers of recyclable materials were active in the city of Juiz de Fora, in the brazilian state of Minas Gerais. In addition, the objective is, still, the recognition of the activity of sorting performed by "scavengers" in order to maximize the reduction, reuse and recycling energy and material waste daily. The proposed methodology is based on the application of the questionnaire Word Health Organization Quality of Life (WHOQOL-100), prepared by the World Health Organization, in order to value the quality of life of the gatherers of recyclable materials, involved, even in educational workshops in order to discuss and organize strategies of health care and scouting to the basement to public policies.
\end{abstract}

Keywords: Quality of life, Scavengers, Municipal Solid Waste, Research

\section{Introduction}

The generation growing and diversified of solid waste in urban environments and their inappropriate management constitute one of the most serious environmental problems [3], demanding solutions involved not only with the increase of recycling, but also with a decrease in the volume of treated material as reject and destined to landfills.
It is the generation of waste, direct reflection of the urban population, of the standard of living that sustains and consumption habits that characterizes it, the causes for the generation of an ever-increasing volume of waste to be collected, processed and prepared properly, with the purpose of do not endanger the quality of life of the population [2].

The gatherer, in a general way, the principle occupies the urban space in a way that struck the

\footnotetext{
${ }^{1}$ Study extracted from the Research Projects "The Management of Municipal Solid Waste, to judge from the outside, from the viewpoint of Reverse Logistics" and "Quality of life of collectors of recyclable materials in Juiz de Fora, Minas Gerais", approved by CNPq: Edictal MCT/ACTION TRANSVERSAL (Law no. 11.540/2007) /CNPq no. 29/2009.
} 
system for the use and operation of the cities. Its presence is often not associated with the operational context and productive, as already identified by national and international surveys. However, it is necessary to recognize that this is an activity that can enlarge the production possibilities through their collection operations.

The research in development presents with the specific aim to assess the quality of life of collectors of recyclable materials by reference to the areas physical, social relations and the environment, in order to identify the variables socio-environmental with the potential to influence the quality of life of those who deal directly with the waste after the discard.

Recognizing and enhancing the work of sorting performed by the collectors of recyclable materials in our urban centers and the potential for reduction, reuse and recycling material and energy of Municipal Solid Waste (MSW) produced daily, it is proposed to pleas for conformation of a management more effective environmental, social and economically of MSW generated in mining town of Juiz de Fora, Brazil.

\section{Practice innovation}

The research in development is to study and analysis of solid waste generated in the city of Juiz de Fora, Minas Gerais, compared to the generation state and federal and in the world, giving the assessment of potential environmental, social, and economic resulting from the implementation of a System of Sustainable Management of Municipal Solid Waste for the city.

A survey of theoretical data and quantitative, referring to the waste and its management, is performed on the basis of academic publications and organs responsible for benchmarking and national statistical municipal, Brazilian Institute of Geography and Statistics (IBGE) and Department of Urban Cleaning (DEMLURB), respectively, in order to identify the configuration of urban conditions contemporary focus.

In referring to the data measured and representative of the reality experienced by the collectors of recyclable materials, the methodology used is based on observational cross-sectional study conducted with 96 scavengers active in the city of Juiz de Fora, among them, adult men and women, in the age of 15 to 74 years. They were included in the study the gatherers who were active in the streets, street fairs and deposits in the data collection period and that officially agreed to participate. Excluding the research those who did not wish to participate in the study.

The completion of data collection stage covered the period of March the September 2010 and was carried out by a group of students for the health area previously selected, trained and instructed to application of the instrument, which is monitored by researchers in order to guarantee the control of data collected.

The assessment about the quality of life of the gatherers of recyclable materials, the focus of the study, was accomplished based on the application of the questionnaire Word Health Organization Quality of Life (WHOQOL-100), prepared by the World Health Organization. The questionnaire consists of a structured instrument from 100 (one hundred) issues included in six domains: physical, psychological, independence, social relationships, environment and spirituality/religion/personal beliefs. Each of the areas mentioned and consisting of 24 (twenty four) facets, in addition to a general facet with questions for the global assessment of quality of life [1].

In addition to the issues cleared on the basis of the application of the WHOQOL-100, used to be issues relating to the characterization of researched in relation to sex, age, marital status, education level, number of children, living situation, a place where he resides and where does the collection of recyclable material, in addition to the determination of possessing or not another type of profession or occupation. Consequently, from the application of the methodology described, was made possible the analysis of the relationship of use and urban scenery, by means of the flow of commuting daily villa-work.

\subsection{Socio-demographic characteristics}

Of the 96 collectors participants in the research, 69 $(71.9 \%)$ were male and $27(28.1 \%)$ were female. In relation to age, $9(9.4 \%)$ were between 15 and 28 years, $23(24 \%)$ had 29 to 39 years and $64(66.7 \%)$ had over 40 years of age.

Of these 96 gatherers participants, 19 (19.8\%) and-ram street residents, $9(9.4 \%)$ reported living alone and $67(69.8 \%)$ lived with the family. In relation to civil status, 42 gatherers $(43.8 \%)$ were single, $24(25 \%)$ were married, $10(10.4 \%)$ separated, $4(4.2 \%)$ were widowed and $8(8.3 \%)$ reported having a stable union. Already in terms of the number of children, $13(13.5 \%)$ have no son, 28 $(29.2 \%)$ have 1 to 2 children, $14(14.6 \%)$ from 3 to 
4 children, $17(17.8 \%)$ from 5 to 7 children and 10 $(10.4 \%)$ possess above 8 children.

As to education, $5(5.2 \%)$ were illiterate, 67 $(69.8 \%)$ had completed elementary school, $9(9.4 \%)$ complete basic education, $5(5.2 \%)$ incomplete secondary education, $8(8.3 \%)$ completed the high school and $1(1 \%)$ had a higher education. The majority of respondents, $55(57.3 \%)$ works only with the picking of recyclable materials, while $33(34.4 \%)$ have or had some other profession or occupation, in addition to picking.

\section{Findings}

Amongst the dimensions of the WHOQOL-100, the data assessed and examined by the research shows that the field of the environment has pointed out escores lower than the other.

Table 1

The 6 domains and the 24 facets included in the WHOQOL-100

\begin{tabular}{|l|}
\hline \multicolumn{1}{|c|}{ Dimensions of the WHOQOL-100 } \\
\hline Domain Physical \\
1. Pain and discomfort \\
2. Energy and fatigue \\
3. Sleep and rest \\
\hline Domain Psychological \\
4. Positive feeling \\
5. Thinking, learning, memory and concentration \\
6. Self-esteem \\
7. Body image and appearance \\
8. Negative feeling \\
\hline Domain Independence \\
9. Mobility \\
10. Activities of daily living \\
11. Dependence on medication or treatments \\
12. Working capacity \\
\hline Domain Social Relationships \\
13. Personal relationships \\
14. Social support \\
15. Sexual activity \\
Domain Environment \\
16. Physical safety and security \\
17. Home environment \\
18. Financial resources \\
20. Opealth and social care \\
21. Leisure opportunities \\
22. Physical environment \\
23. Transport \\
Spirituality / Religion / Personal beliefs \\
\hline
\end{tabular}

On the basis of the weights cleared, it identifies the relationship of the population in study with the area of the city is not negligible, in addition, the non-recognition for the work formal, amplified by means of the social rejection, who is of course through the challenge of the presence of their bodies and means of work in the urban landscape, indicates that there is a perception - reported on by them and found in the research - the condition of social exclusion.

\section{Discussion}

In short, the research has provided the identification the need for recognition of the opportunities created from the waste - characteristic of the habits of contemporary life - and of the imperative development of efficient techniques for the utilization material and energy of the same. This attitude would potentiate the reduction of production costs on the basis of the fall in the costs of raw materials and transport, in addition to the environmental benefits and social.

Looking at the social issues, the research is still in development, involving the collectors in educational workshops for discussion and systematic approach of a strategy of care to the health that would give us the benchmarking of basement on public policies and the recognition of needs related to the work of these environmental agents, known simply as collectors.

\section{References}

[1] Trabalho apoiado pela Incubadora Tecnológica de Cooperativas INTECOOP/UFJF - Proó-Reitoria de Extensão e Cultura.

[2] Fleck MPA. Versão em português dos instrumentos de avaliação de qualidade de vida (whoqol) 1998. Organização Mundial da Saúde, 1998. Disponível em: http://www.ufrgs.br/psiq/whoqol.html Acessado em: 01/novembro/2009.

[3] Pecora, Vanessa; Velázquez, Sílvia Maria Stortini González; Coelho, Suani Teixeira. Aproveitamento do biogás proveniente dos resíduos sólidos urbanos para geração de energia elétrica: estudo de caso em São Paulo. Centro Nacional de Referência em Biomassa - CENBIO. São Paulo, 2009

[4] Shimura, Susumu; Yokoda, Isamu; Nitta, Yoshitaka. Research for MSW flow analysis in development nations. Journal of Material Cycles and Waste Management, v. 3. Shizuoka, Japan. 48-59. Abril, 2001 